\title{
ANALYSIS OF THE THERMOVISION DIAGNOSTICS POTENTIAL IN THE LIGHT SYSTEM ELEMENTS
}

\author{
M. Lukasiewicz ${ }^{*}$, P. Falęcki ${ }^{* *}$, T. Kalaczyński ${ }^{* * *}$, B. Żóltowski ${ }^{\dagger}$, J. Musial $^{\ddagger}$, \\ J. Wilczarska ${ }^{\ddagger}$, R. Kostek ${ }^{\S}$
}

\begin{abstract}
The lighting system of motor vehicles is an important element that affect significantly the safety of the road users. According to the current regulations, the elements of lighting systems are subject to homologation. The given type of a lighting system is designed to use in the particular type of the vehicle. Proper diagnostics of the lighting system is an important part of the maintenance work. This paper analyzes the possibility of using thermovision tests of selected lighting system components on the example of Skoda Superb head-light diagnostics tests.
\end{abstract}

Keywords: diagnostics inference, vehicle lighting system, thermovision tests

\section{Introduction}

The vehicle lighting system must fulfil two most important tasks: to assure the visibility of the car and to light up the road in front of the car. These two tasks can be summarized with a simple statement: " to see others and to be seen on the road”. The significant development of car mechanics and electronics also does not avoid issues related to the lighting technology used in motor vehicles. Current constructions of car headlights can guarantee a suitable quality of the visibility on the road, if only high-efficiency luminaires are applied. Light sources with the appropriate energy and light parameters are expensive, which is a big disadvantage in modernizing the lighting in vehicles. Maintenance of the lighting installation in a proper technical condition requires systematic and careful control. The proper functioning of external lighting is directly related to the safe usage of the vehicle (Kaźmierczak et al., 2011). Lighting control usually includes: checking the position of the headlamps, preliminary testing of the installation (diagnosing the operation), control of the luminous intensity of signal lights, measurement of lighting intensity for passing lights and measurement of the luminous intensity of driving lights. There are less frequent diagnostic tests to check the remaining operational parameters of car headlights. Authors in this paper set to assess the diagnostic potential of the implementation of thermovision methods in diagnostics studies of Skoda Superb reflectors equipped with various types of light bulbs. Along with the development of technology in automotive vehicles, a growing trend in the construction of vehicles of electronic systems allowing to increase travel safety is observed. In recent years, we have observed major

Marcin Łukasiewicz, PhD.: Faculty of Mechanical Engineering, University of Science and Technology, Al. prof.

S. Kaliskiego 7, Bydgoszcz; PL, mlukas@utp.edu.pl.

** Paweł Falęcki, Eng.: Faculty of Mechanical Engineering, Al. prof. S. Kaliskiego 7, Bydgoszcz; PL, faleciak@op.pl.

*** Tomasz Kałaczyński, PhD.: Faculty of Mechanical Engineering, University of Science and Technology, Al. prof. S.

† Prof, Bogdan Żółtowski, PhD.: Faculty of Mechanical Engineering, University of Science and Technology, Al. prof. S. Kaliskiego 7, Bydgoszcz; PL, bogzol@utp.edu.pl.

‡ Prof. Janusz Musiał, PhD.: Faculty of Mechanical Engineering, University of Science and Technology, Al. prof. S. Kaliskiego 7, Bydgoszcz; PL, jamusual@utp.edu.pl.

抹 Joanna Wilczarska, PhD.: Faculty of Mechanical Engineering, University of Science and Technology, Al. prof. S. Kaliskiego 7, Bydgoszcz; PL, joanna.wilczarska@utp.edu.pl.

$\S \quad$ Robert Kostek, PhD.: Faculty of Mechanical Engineering, University of Science and Technology, Al. prof. S. Kaliskiego 7, Bydgoszcz; PL, robertkostek@op.pl. 
changes in vehicle lighting systems. The modular design of modern headlights results in a more efficient use of the light source while increasing difficulty of headlights maintenance and diagnostics. In the light of the above arguments, more attention should be paid to the problem of diagnostic susceptibility in the modern construction of car headlights and the difficult process of disassembly of their components (Lukasiewicz et al., 2013).

Following the discussion above, the authors suggest that there is a necessity to propose new methods for the assessment of the technical condition of lighting systems that would allow the implementation of a non-assembly diagnostic procedure (Gustof, 2013). One of the group of non-assembly methods to assess the technical condition of technical objects is thermovision with thermal imaging. This method uses a special type of television that records the heat emitted by objects in its field of view, and more specifically - the emission of infrared radiation. In the thermovision camera, the infrared radiation detector is a transducer that absorbs the energy of this radiation and converts it into a signal in the form of voltage or the intensity of the current. By measuring infrared radiation sent by a given object as a result, we measure its temperature (Więcek, 2010). The practical application of thermovision methods in diagnostics is not a simple matter, because due to the high sensitivity of the detectors and the influence of external factors, the reading of the results and their correct interpretation requires experience and knowledge on the part of the diagnostician (Kałaczyński et al., 2014).

\section{Methods}

During the investigations, the temperature distribution on the casing and front surface of the Skoda Superb headlight serial number 3U1941018H was verified,- by examining the temperatures to which the casing and the front surface of the reflector warm up under the influence of a specific light source. The tested reflector includes the following types of light source and types of light bulbs: standing lights (light bulb type W5W), passing lights (light bulb type H7), driving lights (light bulb type H3, 55W), fog lights (light bulb type H3, 100W), direction indicator light (light bulb type PY21W). For the verification needs of thermovision methods usefulness in this paper many tests were carried out on the dedicated test bench shown in Figure 1.

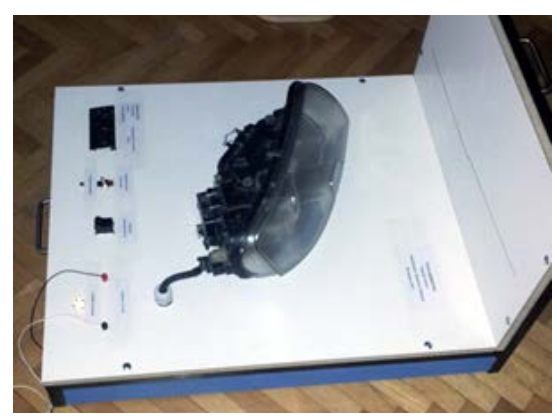

Fig. 1: Test stand in the laboratory

The test stand in the laboratory reflects the lighting system that is possible to obtain in real conditions in the vehicle. Investigations were conducted in three planes:

- plane A - reflector front surface,

- plane B - upper casing of the headlight,

- plane $\mathrm{C}$ - rear casing of the headlight.

The tests were carried out using a FLIR i5 infrared camera. The surrounding temperature in the laboratory was 22 Celsius degrees, the emissivity factor of the camera was established at 0.8 value. Based on preliminary tests, it has been established that the duration of tests for each plane will be 20 minutes, and measurements will be made at selected measurement points every two minutes. For research in this work, the following lighting configurations were determined in the examined headlamp:
a) direction indicator lamp (state S1),
b) standing lights (state S2),
c) passing lights and standing lights (state S3), 
d) driving lights and standing lights (state S4),

e) fog lights, passing lights and standing lights (state S5),

f) fog lights, driving lights and standing lights (state S6).

Figure 2 presents examples of test results obtained with a thermovision camera during the test of direction indicator lights in plane A - front surface of the reflector.
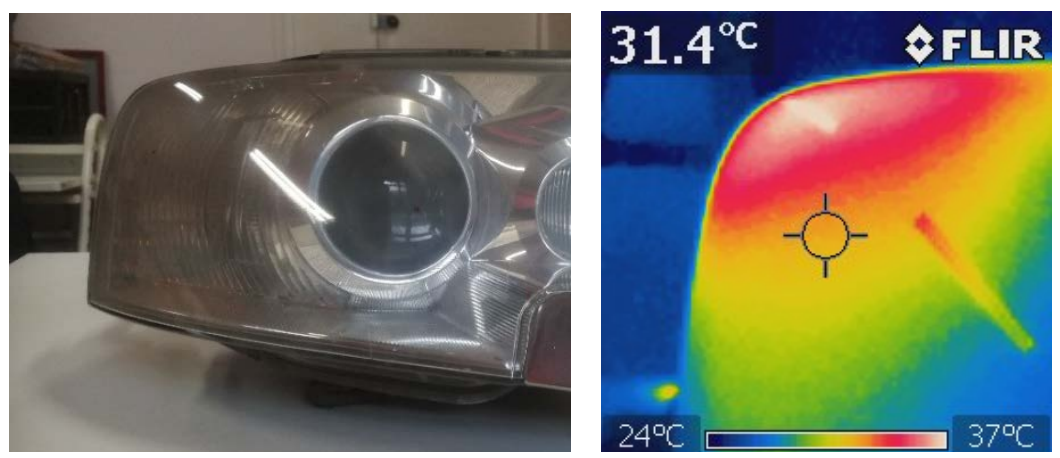

Fig. 2: Reflector view and thermogram of the analysed indicator light in the tested plane

Based on the obtained test results, the temperature values were determined for the three measuring planes. Figure 3 presents the final results of thermographic measurements in three measuring planes for the assumed duration of the experiment during the analysis of the direction indicator lamps.

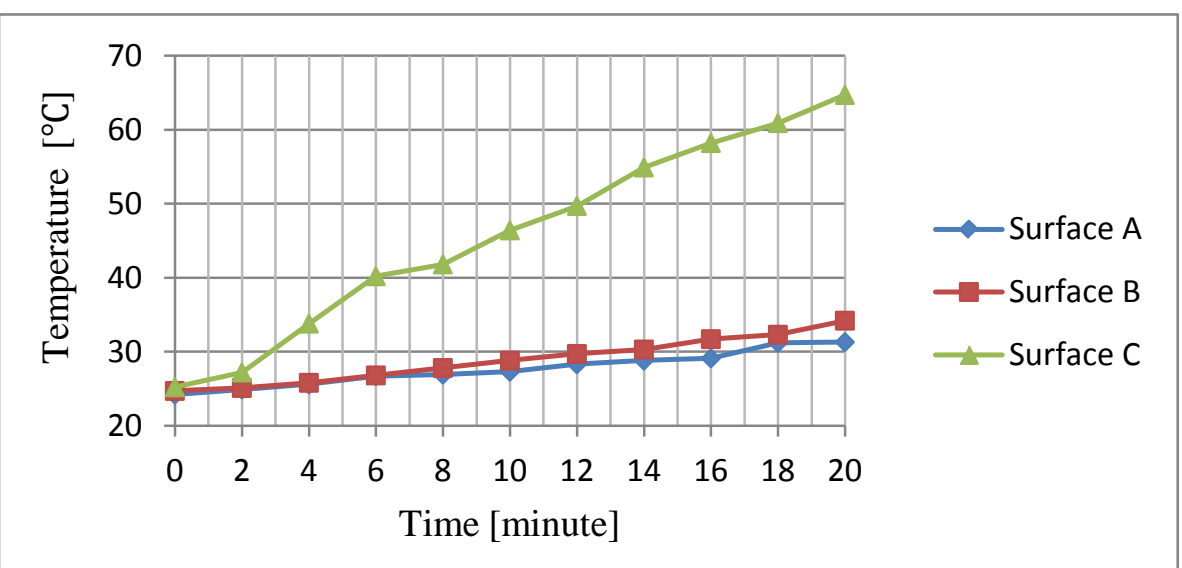

Fig. 3: List of results obtained during the analysis of the indicator lights - state S1

Similarly, tests for the other assumed research conditions were carried out. The results were compiled for the designated measurement planes. Figure 4 presents an example of the results obtained for the plane A.

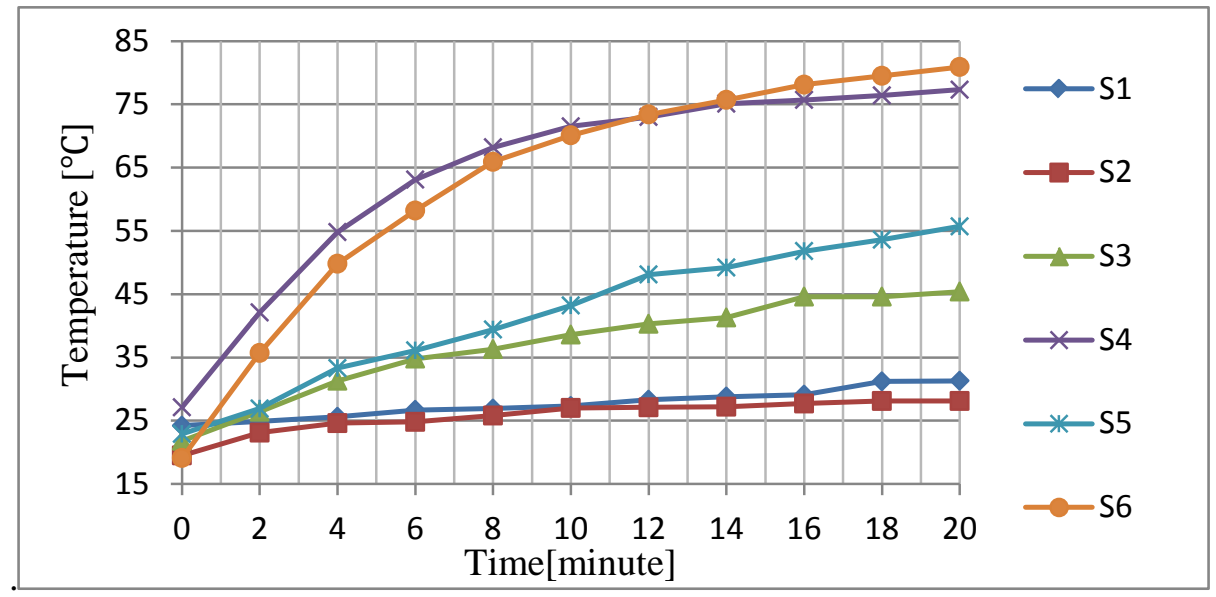

Fig. 4: List of results obtained during all light analysis in plane A 
Table 1 presents the final list of the results of the maximum values of temperatures obtained during measurements in the reflector measurement planes for given lighting states configurations.

Tab. 1: Comparison of the maximum values of temperatures in Celsius degree obtained during tests

\begin{tabular}{ccccccc} 
& State S1 & State S2 & State S3 & State S4 & State S5 & State S6 \\
\hline Plane A & 31.3 & 28.1 & 45.4 & 77.3 & 55.7 & 80.9 \\
\hline Plane B & 34.2 & 28.6 & 75.1 & 65.4 & 72.6 & 70.1 \\
\hline Plane C & 64.7 & 25.3 & 42.1 & 32.0 & 64.5 & 44.4 \\
\hline
\end{tabular}

\section{Conclusions}

This paper evaluates the diagnostic potential of thermovision tests in the diagnosis of the vehicle's lighting system. The use of thermovision with thermal imaging method allowed the visualization of the temperature distribution on the reflector surface, and the analysis of thermographic images indicated differences in the temperature value at the tested measurement points.

During the detailed analysis of the results, it was found that the maximum temperatures for a given light source measured in different planes produced different values. On this basis, it can be concluded that the maximum temperature gradients in the range from $25,3{ }^{\circ} \mathrm{C}$ to $80,9{ }^{\circ} \mathrm{C}$ could have an unfavorably influence on headlight construction and cause a local weakness of the material, which could lead to the damage of the headlight.

Therefore, it is important to use thermovision methods to support the process of assessing the technical condition during the exploitation period. The algorithm of research procedure using thermovision diagnostic methods is a tool for constructors to optimize the construction of lighting system components including points submitted to high thermal load.

\section{References}

Gustof P., (2013) Badania techniczne z diagnostyką pojazdów samochodowych, Wydawnictwo Politechniki Śląskiej, Gliwice.

Kałaczyński T., Łukasiewicz M., Kasprowicz T, Liss M. (2014) The use of thermographic image analysis in the assessment of brake system. 13th International Technical System Degradation Conference Liptovsky Mikulas, pp. 126-128.

Kaźmierczak P., Łukasik M., Moćko W. (2011) Badania fotometryczne i kolorymetryczne urządzeń oświetleniowych pojazdów, Instytut Transportu Samochodowego, Warszawa.

Łukasiewicz M., Kałaczyński T., Kasprowicz T, Liss M. (2013) The exploited machine engines technical state assessment with aplicability of LMS Virtual.Lab, V Ukrainian-Polish Scientific Dialogues KhmielnytskyYaremche 2013, pp. 237-243.

Więcek B. (2010) Wybrane zagadnienia współczesnej termowizji w podczerwieni. Politechnika Łódzka, ISBN 9788372833440. 